\title{
Lipoprotein(a) is not related to markers of insulin resistance in pregnancy
}

\author{
Jelena Todoric ${ }^{1,2}$, Ammon Handisurya ${ }^{3}$, Karoline Leitner ${ }^{4}$, Juergen Harreiter ${ }^{4}$, Gregor Hoermann² \\ and Alexandra Kautzky-Willer ${ }^{4^{*}}$
}

\begin{abstract}
Background: Dyslipidemia, a major risk factor for cardiovascular disease is a common finding in patients with type 2 diabetes and among women with gestational diabetes. Elevated levels of lipoprotein(a) [Lp(a)] are linked to increased risk of cardiovascular disease. However, its relationship with insulin resistance, type 2 diabetes and gestational diabetes is controversial and unproven. Here we aimed to clarify whether $L p(a)$ levels are associated with insulin sensitivity in pregnancy.
\end{abstract}

Methods: Sixty-four women with gestational diabetes and 165 with normal glucose tolerance were enrolled in the study. Fasting Lp(a) serum levels were measured in all women at 24-28 weeks of gestation.

Results: In pregnancy, there was no significant difference in serum $L p(a)$ concentrations between the two groups. Its level did not correlate with markers of insulin resistance (HOMA-IR), insulin sensitivity (HOMA-S\%), pancreatic beta-cell function (HOMA-B\%) and insulin sensitivity in dynamic conditions (OGIS). In addition, fasting glucose and insulin levels and those throughout an oral glucose tolerance test were independent of $L p(a)$ concentrations in our study group.

Conclusions: $L p(a)$ levels in pregnant women do not differ with respect to the presence or absence of gestational diabetes. Although influenced by some components of the lipid profile, such as triglycerides and HDL-C, insulin resistance in pregnancy is not affected by $L p(a)$.

Keywords: Lipoprotein(a), Pregnancy, Gestational diabetes mellitus, Insulin resistance

\section{Background}

Lipoprotein(a) $[\mathrm{Lp}(\mathrm{a})]$ is a plasma lipoprotein that consists of an low-density lipoprotein cholesterol (LDL-C) particle and the glycoprotein apolipoprotein(a) covalently linked to apolipoprotein B100 of the LDL-C particle [1]. There are strong genetic and epidemiological data supporting a causal relationship between elevated $\mathrm{Lp}$ (a) concentrations and the development of atherosclerosis and cardiovascular disease (CVD) [2-4]. Type 2 diabetes (T2D) and CVD share common risk factors, including obesity, hyperinsulinemia and dyslipidemia [5]. Both diseases can also be prevented or treated more effectively if they are diagnosed early and there is substantial interest in identifying new risk factors involved in their development. Lipid abnormalities

\footnotetext{
* Correspondence: alexandra.kautzky-willer@meduniwien.ac.at ${ }^{4}$ Department of Internal Medicine III, Division of Endocrinology and Metabolism, Medical University of Vienna, Waehringer Guertel 18-20, Vienna 1090, Austria

Full list of author information is available at the end of the article
}

frequently observed in subjects with insulin resistance and T2D are hypertriglyceridemia, low high-density lipoprotein cholesterol (HDL-C), and an increased fraction of small, dense LDL-C particles [6]. However, previous reports regarding $L p(a)$ levels and $T 2 D$ are conflicting [7]. Decreased Lp(a) levels in response to hyperinsulinemia $[8,9]$ and a negative relationship between $\mathrm{Lp}(\mathrm{a})$ levels and the incidence of T2D have been reported previously $[10,11]$. In contrast, some studies have shown a strong positive association between T2D and elevated Lp (a) levels $[12,13]$. Similar Lp(a) concentrations in subjects with T2D and healthy controls have been reported in one study [14]. No studies so far have investigated the association between $\mathrm{Lp}(\mathrm{a})$ and insulin sensitivity parameters in gestational diabetes mellitus (GDM).

GDM, defined as glucose intolerance that begins or is first detected during pregnancy affects $7 \%$ of all pregnancies [15-17]. The majority of patients with GDM have beta- cell 
dysfunction associated with insulin resistance [18]. The atherogenic lipid profile is a common finding during the second half of pregnancy and the mechanisms underlying such alterations of lipid metabolism are not fully understood $[19,20]$. However, dyslipidemia during pregnancy may also be a pathological finding suggesting the development of metabolic syndrome. For example, elevated triglyceride (TG) levels have been reported in women with GDM [21] and were associated with diagnosis of GDM [22].

Thus, the goal of this study was to analyze the relationships between Lp(a) levels and parameters of glucose metabolism and insulin sensitivity in patients with GDM and healthy control women during pregnancy.

\section{Methods}

\section{Study population}

Women enrolled in this study were recruited from the outpatient clinic of the Division of Endocrinology and Metabolism at the Medical University of Vienna. Two hundred and twenty nine pregnant women of a similar age and body mass index (BMI) were recruited via universal screening for GDM that was performed with a $2 \mathrm{~h}, 75 \mathrm{~g}$ oral glucose tolerance test (OGTT) between the 24th and 28th weeks of gestation. Sixty- four women were diagnosed with GDM and 165 had a normal glucose tolerance (NGT). Most women were Caucasians (95,6\%; 60 GDM and $159 \mathrm{NGT}$ ), whereas $1,7 \%$ were of African origin (1 GDM and 3 NGT) and 2,6\% were Asian (3 GDM, 3 NGT). None of these women had a history of GDM or any history of impaired glucose tolerance. Fasting Lp (a) concentrations were measured in all women. All participants provided written informed consent, the study was conducted in accordance with the Declaration of Helsinki (2008) and approved by the ethics committee of the Medical University of Vienna. GDM was diagnosed following the recommendations of the American Diabetes Association [23].

\section{$75 \mathrm{~g}$ OGTT}

A 75-g OGTT was performed after a $12 \mathrm{~h}$ overnight fast. Plasma glucose and insulin concentrations were measured before and 30,60, 90, and $120 \mathrm{~min}$ after the ingestion of the glucose solution. Venous blood sera were obtained by centrifugation and analyzed immediately or frozen at $-80^{\circ} \mathrm{C}$ until further analysis.

\section{Assays}

$\mathrm{Lp}$ (a) was quantified using the turbidimetric LPALX assay (Roche) on a cobas c 701 analyzer (Roche) according to the recommendation of the manufacturer. The assay was independent of apolipoprotein(a) isoform size. Hormones, metabolic and kidney function parameters were measured via routine tests in a certified laboratory at the Department of Laboratory Medicine of the Medical University of Vienna.

\section{Data analysis}

The trapezoidal rule was used to determine the area under the concentration curve of glucose, insulin and C-peptide (AUCg, AUCi and AUCcp, respectively) during the OGTT. The homeostasis model assessment (HOMA) was used to evaluate insulin resistance (HOMA-IR), insulin sensitivity indexes (HOMA-S\%) and steady state beta-cell function (HOMA-B\%). The HOMA Calculator software v2.2.2 (http://www.dtu.ox.ac.uk/index.php?maindoc=/homa/ index.php) was utilized for these calculations [24]. During OGTT, dynamic insulin sensitivity was assessed from the oral glucose insulin sensitivity index (OGIS) [25].

\section{Statistical analyses}

Data are presented as mean \pm SE. Distributions of continuous variables were tested for normality using the Shapiro-Francia test, and, if appropriate, the natural log transformations of skewed variables were applied in subsequent analyses. Relationships between continuous variables were evaluated using Spearman rank correlation coefficients. Multiple linear regression models were constructed to examine factors that were associated with $\mathrm{Lp}(\mathrm{a})$ concentration. Two-way ANOVA was performed to evaluate differences between the groups. Statistical analyses were performed using SPSS software (SPSS 17.0, Chicago, IL). A $P$ value of $<0.05$ was considered statistically significant.

\section{Results}

Characteristics of the study population are described in Table 1 . As shown, patients with GDM had significantly higher fasting glucose, insulin, C-peptide, A1C, TG and HOMA-IR whereas HOMA-S\%, the HDL-C and LDL-C levels were lower than in the control group (GDM vs NGT; $\mathrm{P}<0.001, \mathrm{P}=0.008, \mathrm{P}<0.001, \mathrm{P}<0.001, \mathrm{P}=0.024$, $\mathrm{P}=0.002, \mathrm{P}=0.008, \mathrm{P}=0.005$ and $\mathrm{P}=0.017$, respectively). HOMA-B\% value was lower in the GDM women, but the difference to the control group just failed to reach statistical significance $(\mathrm{P}=0.075)$. Moreover, GDM patients showed significantly higher levels of glucose at all time points during the OGTT (Figure 1A). AUCg, AUCi and AUCcp were significantly increased in women with GDM compared with healthy controls (GDM vs NGT; $18.6 \pm 0.4 \mathrm{~g} / \mathrm{dl} \times 120 \mathrm{~min}$ vs $13.9 \pm 0.2 \mathrm{~g} / \mathrm{dl} \times$ $120 \mathrm{~min}, \mathrm{P}<0.001 ; 11.6 \pm 0.8 \mathrm{U} / \mathrm{l} \times 120 \mathrm{~min}$ vs $8.2 \pm 0.3$ $\mathrm{U} / \mathrm{l} \times 120 \mathrm{~min}, \mathrm{P}<0.001$ and $1177.5 \pm 55.9 \mathrm{ng} / \mathrm{ml} \times$ $120 \mathrm{~min}$ vs $940.2 \pm 25.9 \mathrm{ng} / \mathrm{ml} \times 120 \mathrm{~min}, \mathrm{P}<0.001$, respectively). The OGIS showed lower values in patients with GDM compared with NGT women $(470.4 \pm 9.7 \mathrm{ml} \times$ $\min ^{-1} \times \mathrm{m}^{-2}$ vs $\left.525 \pm 3.8 \mathrm{ml} \times \min ^{-1} \times \mathrm{m}^{-2}, \mathrm{P}<0.001\right)$. The mean of age, BMI, systolic and diastolic blood pressure, $\mathrm{C}$-reactive protein (CRP), total cholesterol, creatinine, 
Table 1 Baseline characteristics, metabolic and hormonal parameters in women with GDM and healthy controls

\begin{tabular}{|c|c|c|c|}
\hline & $\begin{array}{l}\text { GDM } \\
n=64\end{array}$ & $\begin{array}{c}\text { NGT } \\
n=165\end{array}$ & $P$ \\
\hline Age, years & $33.6(0.7)$ & $32.6(0.4)$ & 0.228 \\
\hline $\mathrm{BMl}, \mathrm{kg} / \mathrm{m} 2$ & $28.9(0.7)$ & $27.2(0.4)$ & 0.055 \\
\hline Parity & $1.3(0.2)$ & $1.1(0.1)$ & 0.110 \\
\hline $\begin{array}{l}\text { Systolic blood } \\
\text { pressure (mmHg) }\end{array}$ & $112.9(1.2)$ & $109.9(0.9)$ & 0.082 \\
\hline $\begin{array}{l}\text { Diastolic blood } \\
\text { pressure (mmHg) }\end{array}$ & $70.4(1.1)$ & $69.7(0.8)$ & 0.664 \\
\hline Fasting glucose, mg/dl & $87.4(1.4)$ & $78.4(0.5)$ & $<0.001$ \\
\hline Fasting insulin, mU/l & $14.3(0.9)$ & $11.4(0.5)$ & 0.008 \\
\hline Fasting C-peptide, $\mu \mathrm{g} / \mathrm{l}$ & $2.5(0.1)$ & $1.6(0.1)$ & $<0.001$ \\
\hline $\mathrm{A} 1 \mathrm{C}, \%$ & $5.2(0.1)$ & $4.8(0.1)$ & $<0.001$ \\
\hline HOMA-IR & $1.8(0.1)$ & $1.4(0.1)$ & 0.002 \\
\hline HOMA-S\% & $72.4(7.5)$ & $92.1(3.8)$ & 0.008 \\
\hline HOMA-B\% & $151.2(7.5)$ & $166.7(4.6)$ & 0.075 \\
\hline Triglycerides, mg/dl & $195.3(8.3)$ & $173.4(6.5)$ & 0.024 \\
\hline Total cholesterol, mg/dl & $246.9(5.7)$ & $261.5(3.7)$ & 0.051 \\
\hline HDL cholesterol, mg/dl & $68.9(2.1)$ & $75.7(1.2)$ & 0.005 \\
\hline LDL cholesterol, mg/dl & $133.9(5.3)$ & $147.8(2.8)$ & 0.017 \\
\hline $\mathrm{CRP}, \mathrm{mg} / \mathrm{dl}$ & $1.2(0.3)$ & $0.9(0.6)$ & 0.471 \\
\hline Creatinine, mg/dl & $0.60(0.01)$ & $0.62(0.01)$ & 0.084 \\
\hline Estradiol, pg/ml & $10113.2(689.6)$ & $11056.8(447.8)$ & 0.308 \\
\hline Progesterone, ng/ml & $76.9(6.9)$ & $79.2(3.5)$ & 0.753 \\
\hline
\end{tabular}

Variables are presented as mean \pm S.E. The statistical significance of differences between the study groups was determined by ANOVA. The $P$ values

correspond to the differences between GDM and NGT women. Statistically significant $P$ values are labeled with bold text.

estradiol and progesterone was similar for patients and controls.

The mean level of Lp(a) was 40,89+/-5,02 $\mathrm{mg} / \mathrm{dl}$ and $39,47+/-3,37 \mathrm{mg} / \mathrm{dl}$ in patients with GDM and healthy women, respectively and there was no statistically significant difference in $\mathrm{Lp}(\mathrm{a})$ concentrations between the two groups (Figure 1B). Most of the variables traditionally linked to T2D including markers of insulin resistance, fasting insulin, HOMA-B\%, HOMA-S\% and HOMA-IR were not associated with the Lp(a) levels (Table 2, Figure 2). Serum Lp(a) levels showed a significant positive correlation with LDL-C and were negatively related to estradiol (Table 2; $\mathrm{P}=0.022$ and $\mathrm{P}=0.019$ respectively). After adjustment for age and BMI, both LDL-C and estradiol emerged as independent predictors of $\mathrm{Lp}(\mathrm{a})$ concentration in multiple linear regression analyses $(\mathrm{t}=2.474, \mathrm{P}=0.014$; $\mathrm{t}=-2.164, \mathrm{P}=0.032$ ).

\section{Discussion}

Previous studies reported conflicting findings regarding Lp (a) concentrations in patients with T2D and its relationship

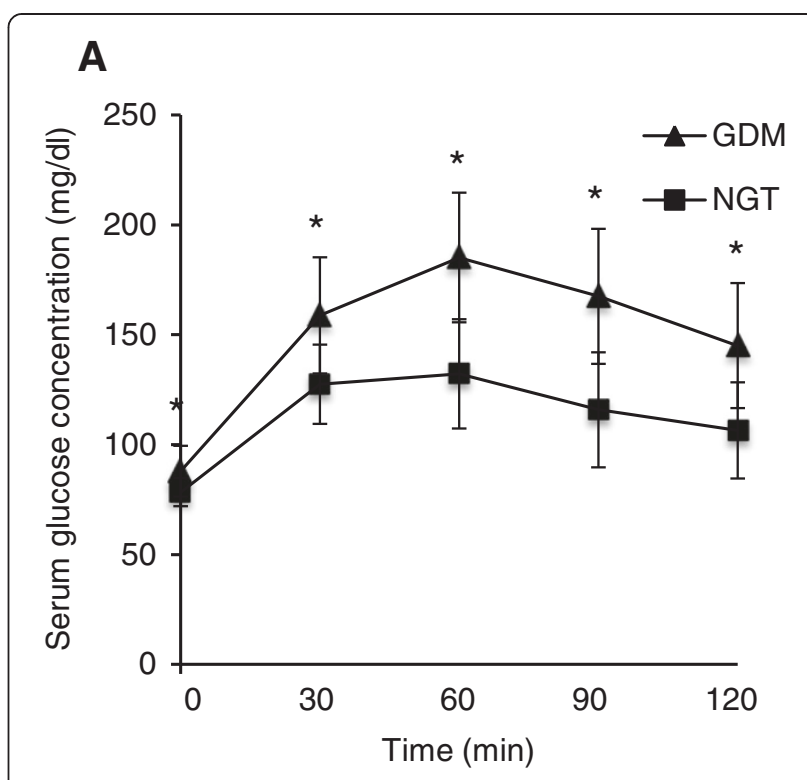

B

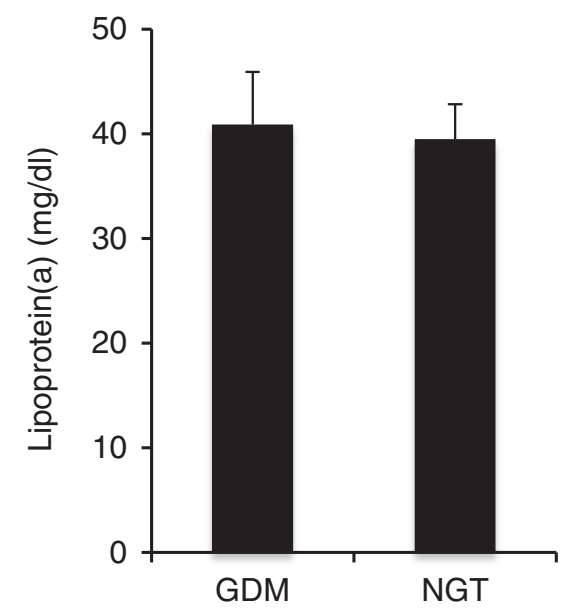

Figure 1 Serum Lp(a) levels in GDM patients and healthy pregnant women. (A) Serum glucose concentrations during OGTT. (B) Fasting Lp(a) serum levels in GDM and NGT women. Data are expressed as mean \pm S.E. ${ }^{*}, P<0.001$.

with insulin resistance [7-14]. In addition, there are limited data currently available on Lp(a) in GDM, which is considered a pre-diabetic state. In the present study we demonstrated that at the time of GDM screening in late pregnancy women with NGT and GDM patients exhibit no difference in $\mathrm{Lp}(\mathrm{a})$ concentration. Furthermore, $\mathrm{Lp}(\mathrm{a})$ did not show any significant correlation with indices of insulin resistance and beta-cell function.

It has been demonstrated previously that insulin could lower $L p(a)$ levels and an inverse relationship between the incidence of diabetes and $L p(a)$ has been reported $[8,13]$. Interestingly, recent data suggested that only extremely high concentrations of $\mathrm{Lp}(\mathrm{a})$, above the threshold level of $46 \mathrm{mg} / \mathrm{dl}$, are associated with less resistance to insulin 
Table 2 Correlations of Lp(a) with metabolic and insulin sensitivity parameters in the whole study group

\begin{tabular}{ccc}
\hline & $\boldsymbol{r}_{\boldsymbol{s}}$ & $\boldsymbol{P}$ \\
\hline BMl & -0.075 & 0.291 \\
Fasting glucose, $\mathrm{mg} / \mathrm{dl}$ & -0.013 & 0.850 \\
Fasting insulin, $\mathrm{mU} / \mathrm{l}$ & 0.038 & 0.570 \\
Fasting C-peptide, $\mathrm{\mu g} / \mathrm{l}$ & 0.047 & 0.490 \\
A1C, \% & 0.024 & 0.720 \\
Triglycerides, mg/dl & -0.031 & 0.654 \\
Total cholesterol, mg/dl & 0.073 & 0.286 \\
HDL cholesterol, mg/dl & -0.081 & 0.230 \\
LDL cholesterol, mg/dl & 0.155 & $\mathbf{0 . 0 2 2}$ \\
Estradiol, pg/ml & -0.162 & $\mathbf{0 . 0 1 9}$ \\
Progesterone, $\mathrm{ng} / \mathrm{ml}$ & -0.039 & 0.566 \\
AUCg, g/dl x 120 min & -0.024 & 0.726 \\
AUCi, U/l x 120 min & -0.018 & 0.794 \\
AUCcp, ng/ml x 120 min & -0.013 & 0.844 \\
HOMA-S\% & -0.033 & 0.631 \\
HOMA-B\% & -0.014 & 0.843 \\
OGIS, ml x min ${ }^{-1} \times$ m ${ }^{-2}$ & -0.043 & 0.556 \\
\hline
\end{tabular}

$r_{s}$ Spearman correlation coefficient.

Statistically significant $P$ values are labeled with bold text.

[26]. $L p(a)$ levels are raised in pregnancy and increase during the course of pregnancy $[27,28]$. In most studies $\mathrm{Lp}$ (a) levels reached the maximum in the third trimester and after delivery $\operatorname{Lp}(\mathrm{a})$ concentrations returned to the baseline values [29]. Previous reports have shown different average $\mathrm{Lp}(\mathrm{a})$ levels at their peak in the last trimester of pregnancy. For example, one longitudinal study reported median peak $\mathrm{Lp}$ (a) values of $47,1 \mathrm{mg} / \mathrm{dl}$ [30]. Sattar et al. noted progressive rise in $\mathrm{Lp}(\mathrm{a})$ concentration during normal pregnancy with a maximal level of $27.0 \mathrm{mg} / \mathrm{dl}$ at 35 weeks

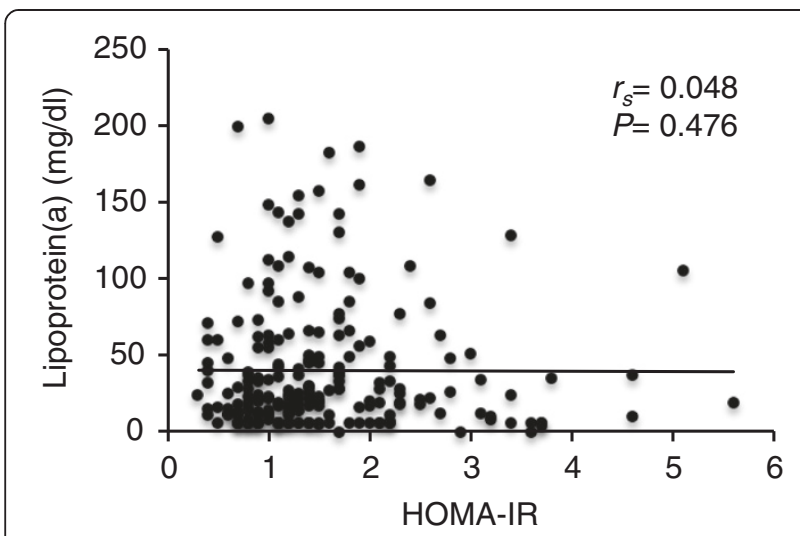

Figure 2 Relationship between insulin resistance and $L p(a)$ in the whole study group. Scatterplot represents the correlation between the $L p(a)$ and insulin resistance parameter HOMA-IR. $r_{s^{\prime \prime}}$ Spearman's correlation coefficient. gestation [31]. In our study subjects Lp(a) levels were just above the physiological concentrations, but did not reach the threshold of $46 \mathrm{mg} / \mathrm{dl}$, which may explain the low correlation with the markers of insulin resistance.

It would be logical to assume that $\operatorname{Lp}(\mathrm{a})$, as a well established risk factor for CVD may be influenced by or may influence other known risk factors such as dyslipidemia or glucose intolerance. For example, blood glucose was correlated with the risk of coronary heart disease in the Framingham Offspring Study and was found to be an independent predictor for cardiovascular mortality $[32,33]$. However, there was no significant correlation between Lp(a) and glycemic biomarkers, fasting glucose, $\mathrm{A} 1 \mathrm{C}$ and AUCg in our study group, which is in agreement with the findings from at least two other studies [34,35]. Small case-studies showed positive correlation between $\mathrm{Lp}(\mathrm{a})$ and HDL-C and a negative correlation between Lp (a) and TG [36,37]. In contrast, a low correlation between $\mathrm{Lp}$ (a) and lipids has been shown previously in a large prospective study of $\mathrm{Lp}(\mathrm{a})$ concentration and risk of T2D in initially healthy US women [11]. Similarly, Lp (a) did not show a significant correlation with other serum lipids in our study group, although we observed a significant positive relationship with LDL-C. This might be explained because LDL-C is included in the cholesterol contained in $L p(a)$ particles. The lack of correlation between $\mathrm{Lp}(\mathrm{a})$ and parameters of glycemia and lipid metabolism is not surprising given that systemic Lp(a) concentrations are highly genetically determined and only a few environmental or physiological factors have been shown to influence serum Lp(a) levels [38].

Consistent with data from others our women with GDM showed slightly lower levels of LDL-C than women with NGT [39]. However, in this study LDL-C postpartum levels were significantly higher in women who had GDM than in women who had NGT during pregnancy. Circulating LDL-C levels may influence the atherothrombotic impact of $\mathrm{Lp}(\mathrm{a})$ and this risk appears to be substantially attenuated among subjects in whom aggressive LDL-C lowering has occurred [40-44]. Similarly, as LDL-C and $\mathrm{Lp}(\mathrm{a})$ are correlated it could be possible that GDM blunted levels of $L p(a)$ during pregnancy. Therefore, future studies are needed to clarify the relationship between $\mathrm{Lp}(\mathrm{a})$ and insulin resistance in women with GDM and NGT postpartum.

\section{Conclusions}

In summary, Lp(a) levels in pregnancy seem to be independent of the presence or absence of GDM. Additionally, our data suggest that the pathophysiological mechanisms of insulin resistance in GDM are not related to the Lp(a) concentration during pregnancy. Further studies are needed to explore the relationship between $\mathrm{Lp}(\mathrm{a})$ and insulin sensitivity in women with NGT and GDM postpartum. 


\section{Abbreviations}

AUCcp: Area under the curve of C-peptide; AUCg: Area under the curve of glucose; AUCi: Area under the curve of insulin; BMI: Body mass index; CRP: C-reactive protein; CVD: Cardiovascular disease; GDM: Gestational diabetes mellitus; HDL-C: High-density lipoprotein cholesterol; HOMA-B\%: Homeostatis model assessments of beta-cell function; HOMA-IR: Homeostasis model assessment of insulin resistance; HOMA-S\%: Homeostasis model assessment of insulin sensitivity; LDL-C: Low-density lipoprotein cholesterol; Lp (a): Lipoprotein(a); T2D: Type 2 diabetes; NGT: Normal glucose tolerance: OGIS: Oral glucose insulin sensitivity index; OGTT: Oral glucose tolerance test; TG: Triglycerides.

\section{Competing interests}

The authors declare that they have no competing interests.

\section{Authors' contributions}

All authors participated in the design and coordination of the study. JT performed the statistical analysis and wrote the manuscript. AH, KL, JH, GH and AKW were involved in the interpretation of the analysis and critically revised the manuscript. All authors read and approved the final version of the manuscript.

\section{Acknowledgements}

This work was supported by a grant from the Jubilaeumsfond of the Austrian Nationalbank to AKW (OeNB 13244) and an unrestricted grant from Takeda to AKW.

\section{Author details}

'Laboratory of Gene Regulation and Signal Transduction, Departments of Pharmacology and Pathology, School of Medicine, University of California San Diego, 9500 Gilman Dr, La Jolla, CA 92093-0636, USA. ²Department of Laboratory Medicine, Medical University of Vienna, Waehringer Guertel 18-20, 1090 Vienna, Austria. ${ }^{3}$ Department of Internal Medicine III, Division of Nephrology and Dialysis, Medical University of Vienna, Waehringer Guertel 18-20, 1090 Vienna, Austria. ${ }^{4}$ Department of Internal Medicine III, Division of Endocrinology and Metabolism, Medical University of Vienna, Waehringer Guertel 18-20, Vienna 1090, Austria.

Received: 27 September 2013 Accepted: 30 September 2013 Published: 1 October 2013

\section{References}

1. Scanu AM, Nakajima K, Edelstein C: Apolipoprotein(a): structure and biology. Front Biosci 2001, 6:546-554.

2. Kamstrup PR, Tybjaerg-Hansen A, Steffensen R, Nordestgaard BG: Genetically elevated lipoprotein(a) and increased risk of myocardial infarction. JAMA 2009, 301(22):2331-2339.

3. Erqou S, Kaptoge S, Perry PL, Di AE, Thompson A, White IR, Marcovina SM, Collins R, Thompson SG, Danesh J: Lipoprotein(a) concentration and the risk of coronary heart disease, stroke, and nonvascular mortality. JAMA 2009, 302:412-423.

4. Clarke R, Peden JF, Hopewell JC, Kyriakou T, Goel A, Heath SC, Parish S, Barlera S, Franzosi MG, Rust S, Bennett D, Silveira A, Malarstig A, Green FR, Lathrop M, Gigante B, Leander K, de FU, Seedorf U, Hamsten A, Collins R, Watkins H, Farrall M: Genetic variants associated with Lp(a) lipoprotein level and coronary disease. N Engl J Med 2009, 361:2518-2528.

5. Meigs JB: Epidemiology of type 2 diabetes and cardiovascular disease: translation from population to prevention: the Kelly West award lecture 2009. Diabetes Care 2010, 33(8):1865-1871.

6. Krauss RM: Lipids and lipoproteins in patients with type 2 diabetes. Diabetes Care 2004, 27(6):1496-1504.

7. Koschinsky ML, Marcovina SM: The relationship between lipoprotein(a) and the complications of diabetes mellitus. Acta Diabeto/ 2003, 40(2):65-76

8. Rainwater DL, Haffner SM: Insulin and 2-hour glucose levels are inversely related to $\mathrm{Lp}(\mathrm{a})$ concentrations controlled for LPA genotype. Arterioscler Thromb Vasc Biol 1998, 18:1335-1341.

9. Habib SS, Aslam M, Shah SF, Naveed AK: Lipoprotein (a) is associated with basal insulin levels in patients with type 2 Diabetes Mellitus. Ara Bras Cardiol 2009, 93:28-33.
10. Kamstrup PR, Benn M, Tybjaerg-Hansen A, Nordestgaard BG: Extreme lipoprotein(a) levels and risk of myocardial infarction in the general population: the Copenhagen City Heart Study. Circulation 2008, 117:176-184.

11. Mora S, Kamstrup PR, Rifai N, Nordestgaard BG, Buring JE, Ridker PM: Lipoprotein(a) and risk of type 2 diabetes. Clin Chem 2010, 56:1252-1260.

12. Habib SS, Aslam M: Lipids and lipoprotein(a) concentrations in Pakistani patients with type 2 diabetes mellitus. Diabetes Obes Metab 2004, 6:338-343.

13. Singla S, Kaur K, Kaur G, Kaur H, Kaur J, Jaswal S: Lipoprotein (a) in type 2 diabetes mellitus: Relation to LDL: HDL ratio and glycemic control. Int J Diabetes Dev Ctries 2009, 29:80-84.

14. Haffner SM, Morales PA, Stern MP, Gruber MK: Lp(a) concentrations in NIDDM. Diabetes 1992, 41(10):1267-1272.

15. Expert Committee on the Diagnosis and Classification of Diabetes Mellitus: Report of the expert committee on the diagnosis and classification of diabetes mellitus. Diabetes Care 2003, 26(Suppl. 1):5-20.

16. American Diabetes Association: Gestational diabetes mellitus (Position Statement). Diabetes Care 2004, 27(Suppl. 1):88-90.

17. Metzger BE, Coustan DM, Organizing Committee: Summary and recommendations of the Fourth International Workshop-Conference on Gestational Diabetes Mellitus. Diabetes Care 1998, 21(Suppl. 2):161-167.

18. Buchanan TA, Xiang AH: Gestational diabetes mellitus. J Clin Invest 2005, 115:485-491.

19. Martin U, Davies C, Hayavi S, Hartland A, Dunne F: Is normal pregnancy atherogenic? Clin Sci (Lond) 1999, 96(4):421-425.

20. Wiznitzer A, Mayer A, Novack V, Sheiner E, Gilutz H, Malhotra A, Novack L: Association of lipid levels during gestation with preeclampsia and gestational diabetes mellitus: a population-based study. Am J Obstet Gynecol 2009, 201(5):482-488.

21. Koukkou E, Watts GF, Lowy C: Serum lipid, lipoprotein and apolipoprotein changes in gestational diabetes mellitus: a cross-sectional and prospective study. J Clin Pathol 1996, 49(8):634-637.

22. Bartha JL, Marín-Segura P, González-González NL, Wagner F, AguilarDiosdado M, Hervias-Vivancos B: Ultrsound evaluation of visceral fat and metabolic risk factors during early pregnancy. Obesity 2007, 15:2233-2239.

23. American Diabetes Association: Diagnosis and classification of diabetes mellitus (Position Statement). Diabetes Care 2009, 32(Suppl. 1):62-67.

24. Caumo A, Perseghin G, Brunani A, Luzi L: New insights on the simultaneous assessment of insulin sensitivity and beta-cell function with the HOMA2 method. Diabetes Care 2006, 29:2733-2734.

25. Mari A, Pacini G, Murphy E, Ludvik B, Nolan JJ: A model-based method for assessing insulin sensitivity from the oral glucose tolerance test. Diabetes Care 2001, 24(3):539-548.

26. Boronat M, Saavedra P, Pérez-Martín N, López-Madrazo MJ, Rodríguez-Pérez C, Nóvoa FJ: High levels of lipoprotein(a) are associated with a lower prevalence of diabetes with advancing age: results of a cross-sectional epidemiological survey in Gran Canaria, Spain. Cardiovasc Diabetol 2012, 11:81.

27. Lippi G, Albiero A, Montagnana M, Salvagno GL, Scevarolli S, Franchi M, Guidi GC: Lipid and lipoprotein profile in physiological pregnancy. Clin Lab 2007, 53(3-4):173-177.

28. Manten GT, Franx A, van der Hoek YY, Hameeteman TM, Voorbij HA, Smolders HC, Westers P, Visser GH: Changes of plasma lipoprotein(a) during and after normal pregnancy in Caucasians. J Matern Fetal Neonatal Med 2003, 14(2):91-95.

29. Manten GT, Voorbij HA, Hameeteman TM, Visser GH, Franx A: Lipoprotein (a) in pregnancy: a critical review of the literature. Eur J Obstet Gynecol Reprod Biol 2005, 122:13-21.

30. Belo L, Caslake M, Santos-Silva A, Pereira-Leite L, Quintanilha A, Rebelo I: Lipoprotein(a): a longitudinal versus a cross-sectional study in normal pregnancy and its levels in preeclampsia. Atherosclerosis 2002, 165(2):393-395.

31. Sattar N, Clark P, Greer IA, Shepherd J, Packard CJ: Lipoprotein (a) levels in normal pregnancy and in pregnancy complicated with pre-eclampsia. Atherosclerosis 2000, 148(2):407-411.

32. Meigs JB, Nathan DM, Wilson PW, Cupples LA, Singer DE: Metabolic risk factors worsen continuously across the spectrum of nondiabetic glucose tolerance. The Framingham Offspring Study. Ann Intern Med 1998, 128:524-533. 
33. Coutinho M, Gerstein HC, Wang Y, Yusuf S: The relationship between glucose and incident cardiovascular events. A metaregression analysis of published data from 20 studies of 95,783 individuals followed for 12.4 years. Diabetes Care 1999, 22(2):233-240.

34. Westerhuis LW, Venekamp WJ: Serum lipoprotein-a levels and glycometabolic control in insulin and non-insulin dependent diabetes mellitus. Clin Biochem 1996, 29(3):255-259.

35. Chandni R, Ramamoorthy KP: Lipoprotein(a) in type 2 diabetic subjects and its relationship to diabetic microvascular complications. World J Diabetes 2012, 3(5):105-109.

36. Sharma S, Merchant J, Fleming SE: Lp(a)-cholesterol is associated with HDL-cholesterol in overweight and obese African American children and is not an independent risk factor for CVD. Cardiovasc Diabetol 2012, 11:10.

37. Hernández C, Chacón P, García-Pascual L, Simó R: Differential influence of LDL cholesterol and triglycerides on lipoprotein(a) concentrations in diabetic patients. Diabetes Care 2001, 24(2):350-355.

38. Fontana P, Mooser V, Bovet P, Shamlaye C, Burnand B, Lenain V, Marcovina SM, Riesen W, Darioli R: Dose-dependent inverse relationship between alcohol consumption and serum Lp(a) levels in black African males. Arterioscler Thromb Vasc Biol 1999, 19(4):1075-1082.

39. Retnakaran R, Qi Y, Connelly PW, Sermer M, Hanley AJ, Zinman B: The graded relationship between glucose tolerance status in pregnancy and postpartum levels of low-density-lipoprotein cholesterol and apolipoprotein B in young women: implications for future cardiovascular risk. J Clin Endocrinol Metab 2010, 95(9):4345-4353.

40. Armstrong WW, Cremer P, Eberle E, Manke A, Schulze F, Wieland H, Kreuzer $H$, Seidel D: The association between serum $L p(a)$ concentrations and angiographically assessed coronary atherosclerosis. Dependence on serum LDL levels. Atherosclerosis 1986, 62(3):249-257.

41. Cantin B, Gagnon F, Moorjani S, Després JP, Lamarche B, Lupien PJ, Dagenais GR: Is lipoprotein(a) an independent risk factor for ischemic heart disease in men? The Quebec Cardiovascular Study. J Am Coll Cardiol 1998, 31(3):519-525.

42. Maher VM, Brown BG, Marcovina SM, Hillger LA, Zhao XQ, Albers JJ: Effects of lowering elevated LDL cholesterol on the cardiovascular risk of lipoprotein(a). JAMA 1995, 274(22):1771-1774.

43. von Eckardstein A, Schulte H, Cullen P, Assmann G: Lipoprotein(a) further increases the risk of coronary events in men with high global cardiovascular risk. J Am Coll Cardiol 2001, 37(2):434-439.

44. Nicholls SJ, Tang WH, Scoffone H, Brennan DM, Hartiala J, Allayee H, Hazen SL: Lipoprotein(a) levels and long-term cardiovascular risk in the contemporary era of statin therapy. J Lipid Res 2010, 51(10):3055-3061.

doi:10.1186/1475-2840-12-138

Cite this article as: Todoric et al.: Lipoprotein(a) is not related to markers of insulin resistance in pregnancy. Cardiovascular Diabetology 2013 12:138.

\section{Submit your next manuscript to BioMed Central and take full advantage of:}

- Convenient online submission

- Thorough peer review

- No space constraints or color figure charges

- Immediate publication on acceptance

- Inclusion in PubMed, CAS, Scopus and Google Scholar

- Research which is freely available for redistribution 